\title{
Blood amino acids profile responding to heat stress in dairy cows
}

\author{
Jiang Guo ${ }^{1,2}$, Shengtao $\mathrm{Gao}^{2}$, Suyu Quan², Yangdong Zhang ${ }^{2}$, Dengpan $\mathrm{Bu}^{1,2,3,4, *}$, and Jiaqi Wang ${ }^{1,2, *}$
}

\author{
* Corresponding Authors: \\ Dengpan Bu \\ Tel: +86-010-62813901, Fax: +86-010-62897587 \\ E-mail: budengpan@126.com \\ Jiaqi Wang \\ Tel: +86-010-62813901, Fax: +86-010-62897587, \\ E-mail: wang-jia-qi@263.net \\ ${ }^{1}$ College of Animal Science and Technology, Hunan \\ Agricultural University, Changsha 410128, China \\ 2 State Key Laboratory of Animal Nutrition, Institute \\ of Animal Science, Chinese Academy of Agricultural \\ Sciences, Beijing 100193, China \\ ${ }^{3}$ Synergetic Innovation Center Of Food Safety and \\ Nutrition, Harbin 150030, China \\ ${ }^{4}$ World Agroforestry Centre, East and Central Asia, \\ Beijing 100081, China
}

Submitted Jun 2, 2016; Revised Nov 7, 2016; Accepted Feb 19, 2017

\begin{abstract}
Objective: The objective of this experiment was to investigate the effects of heat stress on milk protein and blood amino acid profile in dairy cows.

Methods: Twelve dairy cows with the similar parity, days in milk and milk yield were randomly divided into two groups with six cows raised in summer and others in autumn, respectively. Constant managerial conditions and diets were maintained during the experiment. Measurements and samples for heat stress and no heat stress were obtained according to the physical alterations of the temperature-humidity index.

Results: Results showed that heat stress significantly reduced the milk protein content $(\mathrm{p}<0.05)$. Heat stress tended to decrease milk yield $(\mathrm{p}=0.09)$. Furthermore, heat stress decreased dry matter intake, the concentration of blood glucose and insulin, and glutathione peroxidase activity, while increased levels of non-esterified fatty acid and malondialdehyde $(p<0.05)$. Additionally, the concentrations of blood $\mathrm{Thr}$ involved in immune response were increased under heat stress $(\mathrm{p}<0.05)$. The concentration of blood Ala, Glu, Asp, and Gly, associated with gluconeogenesis, were also increased under heat stress $(\mathrm{p}<0.05)$. However, the concentration of blood Lys that promotes milk protein synthesis was decreased under heat stress $(\mathrm{p}<0.05)$.

Conclusion: In conclusion, this study revealed that more amino acids were required for maintenance but not for milk protein synthesis under heat stress, and the decreased availability of amino acids for milk protein synthesis may be attributed to competition of immune response and gluconeogenesis.
\end{abstract}

Keywords: Amino Acids; Heat Stress; Insulin; Milk Protein

\section{INTRODUCTION}

Global warming is one of the biggest challenges of current century [1]. Hyperthermal environment induces heat stress to dairy cows in summer and causes huge losses to the dairy economy. The decreased milk production and conception rate of dairy cows during summer depicts the heat stress on dairy cows [2]. In addition, the components of milk are strongly affected by heat stress. The greater number of somatic cells counted in milk during summer also shows that hyperthermic environment severely affects the quality of milk [3]. Heat stress also reduces the milk fat content of Holstein and Jersey cows [2]. Furthermore, it is found that a hyperthermal environment could also reduce the milk protein content via reduction of casein concentration [1].

Nutritional conditions and metabolism of dairy cows are affected by heat stress. For instance, alteration in post-absorptive metabolism of heat-stressed cows fails to enlist glucose "sparing" mechanisms [4]. Furthermore, because of reduction of feed intake and rise of maintenance requirement, heat-stressed cows may decrease the nutrient availability for milk production [5]. Heat stress has been reported to interfere with nitrogen metabolism and cause nitrogenous repartition in dairy cow, and decreases milk protein content while increasing milk urea concentration [6]. Amino acids of blood are known to synthesize the major components of milk protein in bovine mammary glands. Many studies indicate marked changes of circulating amino acids under catabolic conditions [7]. However, limited information is available concerning changes of circul- 
ating amino acids under heat stress. Therefore, the objective of this study was to investigate the effect of heat stress on milk protein content and blood amino acid profile in dairy cows.

\section{MATERIALS AND METHODS}

\section{Animals and management conditions}

All procedures were carried out in strict accordance with the recommendations in the Guide for Guidelines for Experimental Animals of the Ministry of Science and Technology (Beijing, China). The protocol was approved by the Animal Care and Use Committee of Institute of Animal Science, Chinese Academy of Agricultural Sciences.

The experiment was conducted at the Sino-farm (Beijing, China). Twelve Holstein cows were assigned to two groups in a completely random design. Heat stress group $(\mathrm{HS}$ and $\mathrm{n}=6)$ were performed in summer, and non-heat stress group (NS and $n=6$ ) were performed in autumn. Parity, day in milk (DIM) and milk yield were similar between treatments, the DIM of these cows was $164 \pm 19 \mathrm{~d}$ in HS and $175 \pm 31 \mathrm{~d}$ in NS, the average values of milk yield were $29.7 \pm 5.2 \mathrm{~kg} / \mathrm{d}$ for HS cows and $28.5 \pm 1.8 \mathrm{~kg} / \mathrm{d}$ for NS cows, and the average values of parity were $1.7 \pm 1.0$ in HS and $1.7 \pm 1.0$ in NS. In addition, constant managerial conditions (milking frequency, feeding frequency, and time) and diets were maintained during the experiment. Basal ration was formulated to meet or exceed nutrient requirement recommendations [8]. Ingredients and chemical composition of the basal diet are presented in Table 1. All cows were housed in a free stall barn and were assigned to 12 electronic gate feeders (RIC system, Insentec, Marknesse, Netherlands) with individual identification transponders fitted to each cow to record the intake of each individual meal. Cows were fed the total mixed ration (TMR) daily at 0700 and 1600 $\mathrm{h}$ and the gate feeders were supplied with TMR to allow for $10 \%$ refusals. Cows suffered HS and NS more than three weeks before sampling, respectively. Measurements and samples were collected from July 21 to August 11, 2014 and from October 20 to November 10, 2014.

\section{Measurements and analyses}

To measure the environmental conditions inside the barn, temperatures and relative humidity were recorded daily $(0600,1400$, and $2200 \mathrm{~h}$ ) using thermometer and hygrometer in one instrument panel (Bejing Yaguang Equipment Co. Ltd., Beijing, China). The temperature-humidity index (THI) was calculated using the following formula: $\mathrm{THI}=1.8 \times \mathrm{T}+32-0.55 \times(1-\mathrm{RH}) \times(\mathrm{T} \times 1.8+32-$ 58 ), where $\mathrm{RH}$ was relative humidity expressed as fraction of the unit and $\mathrm{T}$ was ambient temperature expressed as degrees Celsius [1]. Rectal temperature and respiration rate of dairy cows were measured at 0700 and $1400 \mathrm{~h}$ twice a week. Rectal temperatures were measured using a glass mercury thermometer (Nasco, Ft. Atkinson, WI, USA), and respiration rate was determined by counting numbers of flank movements/min for $120 \mathrm{~s}$.
Table 1. Ingredient and chemical composition of the basal diet

\begin{tabular}{|c|c|}
\hline Items & Content \\
\hline \multicolumn{2}{|l|}{ Ingredient (\% of DM) } \\
\hline Alfalfa hay & 10.0 \\
\hline Corn silage & 25.0 \\
\hline Oat hay & 12.9 \\
\hline Ground corn & 3.9 \\
\hline Soybean meal & 8.6 \\
\hline Rapeseed meal & 1.2 \\
\hline Extruded soybean & 1.1 \\
\hline Dry distillers grain & 7.5 \\
\hline Steam-flaked corn & 13.1 \\
\hline Beet pulp & 4.8 \\
\hline Whole cottonseed & 6.6 \\
\hline Condensed molasses fermentation solubles & 2.1 \\
\hline $\mathrm{EB} 100^{1)}$ & 0.7 \\
\hline$X P^{2)}$ & 0.3 \\
\hline Salt & 0.2 \\
\hline Limestone & 0.6 \\
\hline Sodium bicarbonate & 0.7 \\
\hline Potassium bicarbonate & 0.3 \\
\hline Premix ${ }^{3)}$ & 0.3 \\
\hline Total & 100 \\
\hline \multicolumn{2}{|l|}{ Chemical composition (\%) } \\
\hline $\mathrm{NE}_{L}^{4)}(\mathrm{Mcal} / \mathrm{kg})$ & 1.67 \\
\hline$C P$ & 16.04 \\
\hline EE & 5.61 \\
\hline NDF & 36.00 \\
\hline ADF & 23.78 \\
\hline$\left(a^{4)}\right.$ & 0.57 \\
\hline$p^{4)}$ & 0.41 \\
\hline Ash & 7.30 \\
\hline
\end{tabular}

$\mathrm{DM}$, dry matter; $\mathrm{NE}_{1}$ net energy for lactation; $\mathrm{CP}$, crude protein; $\mathrm{EE}$, ether extract; $\mathrm{NDF}$, neutral detergent fiber; $A D F$, acid detergent fiber.

1) EB100 is a mainly saturated free fatty acid fat supplement.

${ }^{2)} \mathrm{XP}$ is a mainly saturate free amino acids supplement.

${ }^{3)}$ Contained (per kilogram of DM) a minimum 250,000 IU of vitamin A; 65,000 IU of vitamin D; 2,100 IU of vitamin E; Fe 400 mg; Cu 540 mg; Zn 2,100 mg; Mn 560 mg; Se $15 \mathrm{mg}$; $35 \mathrm{mg}$; and Co $68 \mathrm{mg}$

${ }^{4)}$ Determined by prediction of CPM-DairyBetav3.

Samples of TMR were collected weekly and dried for $48 \mathrm{~h}$ at $60^{\circ} \mathrm{C}$. Samples were ground through a $1-\mathrm{mm}$ sieve in a Cyclotec 1093 Mill (Tecator 1093, Hoganas, Sweden), and residual dry matter was determined by drying at $105^{\circ} \mathrm{C}$ for $3 \mathrm{~h}$. Chemical composition was determined according to AOAC for ash (method 942.05), crude protein (method 990.13), neutral detergent fiber (method 2002.04), acid detergent fiber (method 973.18), and ether extract (method 920.39) [9].

Cows were milked three times daily (at 0700, 1400, and 1900 h). Milk yield was recorded at each milking, and milk samples (approximately $50 \mathrm{~mL}$ ) were collected weekly and combined at a ratio of 4:3:3 by volume (this ratio reflecting the milk yield of three times). Each milk sample was treated with potassium dichromate as a preservative and then stored at $4^{\circ} \mathrm{C}$ for subsequent analysis of protein using mid-infrared spectrophotometry (BactoScan FC 
CombiFoss 6000, Foss Electric, Hillerød, Denmark).

On days 21 of sample collection period, duplicate blood samples were collected from the median coccygeal vein before the morning feeding into tubes with and without anticoagulant. The samples were centrifuged $\left(3,000 \mathrm{~g}\right.$ for $15 \mathrm{~min}$ at $\left.4^{\circ} \mathrm{C}\right)$ to separate the plasma or serum, which were stored at $-70^{\circ} \mathrm{C}$ for further analysis. Serum was analyzed for non-esterified fatty acid (NEFA) [10]. The concentrations of glucose and insulin in plasma were analyzed using the assay kits (Beijing Furui BioTech Ltd., Beijing, China). The levels of malondialdehyde (MDA) and the activities of glutathione peroxidase (GSH-Px), and superoxide dismutase (SOD) in plasma were determined using the assay kits (Nanjing Jiancheng Biochemical Reagent Co., Nanjing, China). Plasma amino acid profile was determined by automatic amino-acid analyzer (Hitachi, Ltd. Tokyo, Japan).

\section{Statistical analysis}

All statistical analyses were performed using the statistical software package SAS 9.3 (SAS Institute Inc., Cary, NC, USA). Milk yield, dry matter intake (DMI), rectal temperature, respiration rate, milk protein content and yield were analyzed using PROC MIXED procedure of SAS. The model included treatment, week and treatment by week interaction as fixed effects and cow as a random effect. Blood glucose, NEFA, insulin, MDA, GSH-Px, SOD, and amino acids concentration were analyzed using the general linear model procedure of SAS. The $\mathrm{p}<0.05$ was considered statistically significant, and tendencies were indicated if the $\mathrm{p}$ value was between 0.05 and 0.10 .

\section{RESULTS}

Temperature-humidity index, rectal temperature and respiration rate

The Figure 1 shows the course of daily THI during the experimental period. The THI averages were 78.1 in summer (July 21 to August 11) and 54.1 in autumn (October 20 to November 10), respectively. Compared with group NS, rectal temperature of group HS was higher at $0600 \mathrm{~h}$ and $1400 \mathrm{~h}$ ( $\mathrm{p}<0.05$; Table 2). Furthermore, respiration rate of group HS was also higher at 0600 $\mathrm{h}$ and $1400 \mathrm{~h}(\mathrm{p}<0.05)$.

Milk yield, dry matter intake, and milk protein Compared with NS, cows in HS tended to have lower milk yield ( $p=0.09$; Table 3). The DMI in HS was lower than that in NS $(21.0 \mathrm{vs} 17.9 \mathrm{~kg} / \mathrm{d}, \mathrm{p}<0.05)$. Milk protein content was also lower in HS ( $\mathrm{p}<0.05)$. However, there was no difference in milk protein yield between two groups ( $\mathrm{p}>0.05)$.

\section{Antioxidant biomarkers}

Cows of group HS had higher plasma MDA level than those in group NS ( $\mathrm{p}<0.05$; Table 4$)$. However, cows in HS had lower plasma GSH-Px activity compared with NS ( $\mathrm{p}<0.05)$. No difference was observed in SOD activity between NS and HS ( $p>0.05)$.

\section{Blood glucose, non-esterified fatty acid, and insulin}

Compared with group NS, cows of group HS had lower glucose and insulin concentrations ( $\mathrm{p}<0.05$; Table 5 ). However, cows of group HS had higher NEFA concentrations than those in group

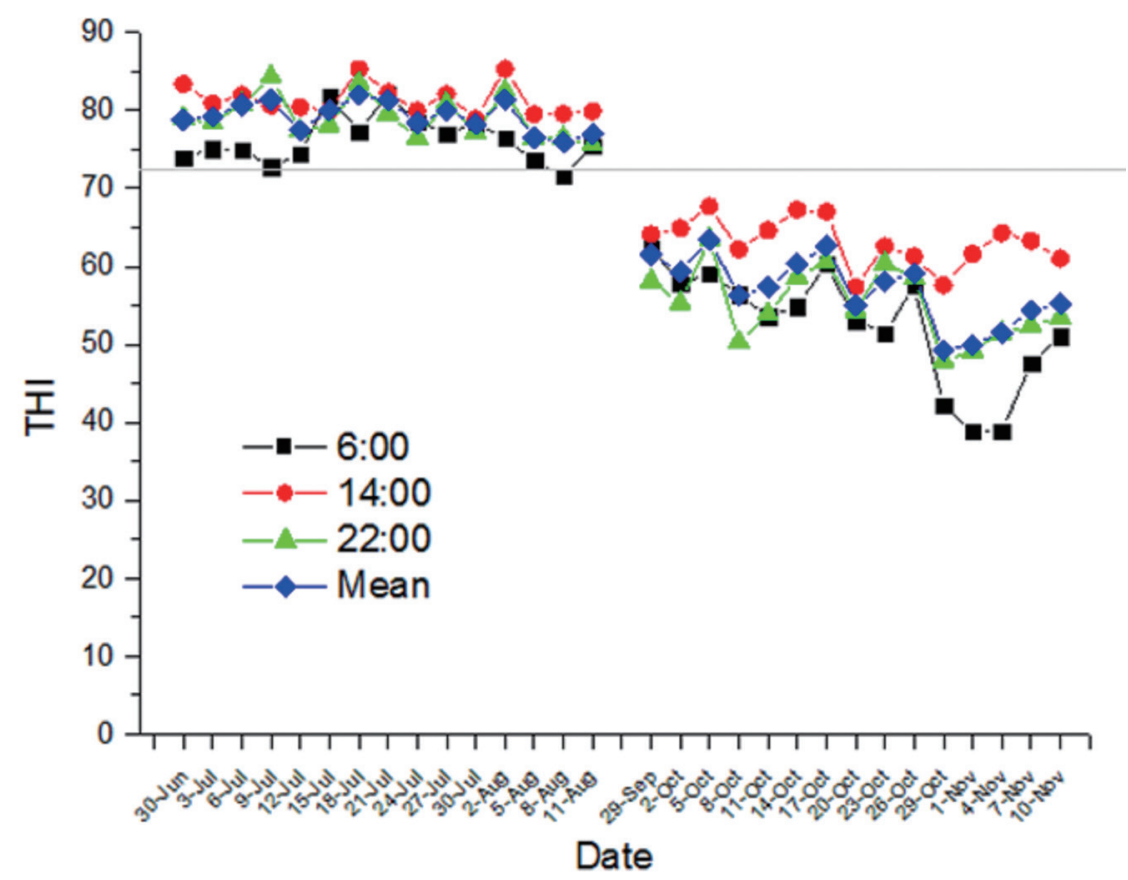

Figure 1. Temperature-humidity index (THI) at 0600, 1400, $2200 \mathrm{~h}$ and mean during the experiment periods. 
Table 2. Rectal temperature (RT) and respiratory rate (RR) of cows observed in summer and autumn

\begin{tabular}{|c|c|c|c|c|c|c|}
\hline \multirow{2}{*}{ Items } & \multicolumn{2}{|c|}{ Treatment } & \multirow{2}{*}{ SEM } & \multicolumn{3}{|c|}{$\mathrm{p}$-value } \\
\hline & $N S^{1)}$ & $\mathrm{HS}^{2)}$ & & Treatment & Week & Treatment×week \\
\hline \multicolumn{7}{|l|}{$\mathrm{RT}\left({ }^{\circ} \mathrm{C}\right)$} \\
\hline $0700 \mathrm{~h}$ & 38.39 & 38.59 & 0.051 & 0.02 & 0.27 & 0.11 \\
\hline $1400 \mathrm{~h}$ & 38.41 & 38.91 & 0.099 & $<0.01$ & 0.05 & 0.20 \\
\hline \multicolumn{7}{|c|}{ RR (breath/min) } \\
\hline $0700 \mathrm{~h}$ & 30.0 & 58.6 & 4.52 & $<0.01$ & 0.07 & 0.14 \\
\hline $1400 \mathrm{~h}$ & 36.3 & 73.4 & 4.98 & $<0.01$ & 0.21 & 0.27 \\
\hline
\end{tabular}

NS, non-heat stress group; HS, heat stress group; SEM, standard error of the mean.

${ }^{1)}$ Cows were raised in autumn. ${ }^{2)}$ Cows were raised in summer.

Table 3. Milk yield, DMI, and milk protein content and yield of cows observed in summer and autumn season

\begin{tabular}{|c|c|c|c|c|c|c|}
\hline \multirow{2}{*}{ Items } & \multicolumn{2}{|c|}{ Treatment } & \multirow{2}{*}{ SEM } & \multicolumn{3}{|c|}{$p$-value } \\
\hline & NS $^{1)}$ & $\mathrm{HS}^{2)}$ & & Treatment & Week & Treatment×week \\
\hline Milk yield (kg/d) & 29.3 & 25.1 & 1.55 & 0.09 & 0.64 & 0.58 \\
\hline DMI (kg/d) & 21.0 & 17.9 & 0.71 & 0.01 & 0.92 & 0.19 \\
\hline \multicolumn{7}{|l|}{ Milk protein, } \\
\hline Content (\%) & 3.50 & 3.24 & 0.082 & $<0.05$ & 0.86 & 0.95 \\
\hline Yield (kg/d) & 1.05 & 0.87 & 0.076 & 0.16 & 0.48 & 0.34 \\
\hline
\end{tabular}

NS, non-heat stress group; HS, heat stress group; SEM, standard error of the mean; DMI, dry matter intake.

${ }^{1)}$ Cows were raised in autumn. ${ }^{2)}$ Cows were raised in summer.

NS $(\mathrm{p}<0.05)$.

\section{Plasma concentration of amino acids}

It was observed that concentration of some amino acids in plasma was affected by HS (Table 6). Compared with group NS, cows of group HS had higher concentrations of total amino acids, Ala, Glu, $\mathrm{Thr}$, and Gly $(\mathrm{p}<0.05)$. Cows tended to have higher Asp concentration in HS ( $\mathrm{p}=0.08)$. Only Lys concentration was lower in group HS $(\mathrm{p}<0.05)$. In addition, there were no significant differences in Arg, Asn, Leu, Ile, Phe, Trp, Met, Gln, Tyr, and Val concentrations between NS and HS ( $>0.05)$.

\section{DISCUSSION}

The THI is considered as an indicator of heat stress in dairy cows. It is traditionally believed that dairy cows begin to be affected when THI exceeds 72 . In the present experiment, the THI aver-

Table 4. The oxidative index and antioxidant enzyme activity collected in summer and autumn season

\begin{tabular}{lcccc}
\hline \multirow{2}{*}{ Items } & \multicolumn{2}{c}{ Treatment } & \multirow{2}{*}{ SEM } & p-value \\
\cline { 2 - 3 } & $\mathbf{N S}^{1)}$ & HS $^{2)}$ & & \\
\hline MAD (nmol/mL) & 2.81 & 3.75 & 0.200 & 0.01 \\
GSH-Px (U/L) & 121.5 & 88.5 & 6.77 & 0.01 \\
SOD (U/mL) & 121.9 & 111.2 & 6.55 & 0.28 \\
\hline
\end{tabular}

NS, non-heat stress group; HS, heat stress group; SEM, standard error of the mean; MAD, malondialdehyde; GSH-Px, glutathione peroxidase; SOD, superoxide dismutase.

1) Cows were raised in autumn.

${ }^{2)}$ Cows were raised in summer. ages exceeded 72 in summer (July 21 to August 11), indicating that dairy cows were subjected to heat stress. In addition, respiration rate and rectal temperature at $1400 \mathrm{~h}$ exceeded $60 \mathrm{breath} / \mathrm{min}$ and $38.9^{\circ} \mathrm{C}$ in summer, respectively. According to Cheng et al [11], dairy cows experienced heat-stressed status during the summer in our study.

Exposure to hyperthermic environment could be responsible for oxidative stress of dairy cows. The results from our study showed that heat-stressed cows had higher level of MDA and lower activity of GSH-Px. It was consistent with previous reports, which showed that hyperthermic environment increased lipid peroxidation and inhibited the activity of antioxidant enzyme [12]. Zuo et al [13] has reported that hyperthermic environment could stimulate intracellular and extracellular superoxide formation. Hydroxyl radical generated by superoxide can attack membrane lipid and initiate lipid peroxidation [14]. Excessive accumulation of MDA may inhibit the activities of antioxidant

Table 5. Blood glucose, non-esterified fatty acid (NEFA) and insulin collected in summer and autumn

\begin{tabular}{lcccc}
\hline \multirow{2}{*}{ Items } & \multicolumn{2}{c}{ Treatment } & \multirow{2}{*}{ SEM } & p-value \\
\cline { 2 - 3 } & NS $^{1)}$ & HS $^{2)}$ & & \\
\hline Glucose $(\mathrm{mg} / \mathrm{dL})$ & 34.5 & 29.5 & 1.12 & $<0.01$ \\
NEFA $(\mu \mathrm{mol} / \mathrm{L})$ & 144.0 & 245.8 & 22.08 & 0.02 \\
Insulin $(\mu / \mathrm{U} / \mathrm{mL})$ & 11.27 & 6.14 & 1.273 & 0.02 \\
\hline
\end{tabular}

NS, non-heat stress group; HS, heat stress group; SEM, standard error of the mean; NEFA, non-esterified fatty acid.

1) Cows were raised in autumn.

2) Cows were raised in summer. 
Table 6. Plasma amino acids collected in summer and autumn season

\begin{tabular}{lcccr}
\hline \multirow{2}{*}{ Items } & \multicolumn{2}{c}{ Treatment } & \multirow{2}{*}{ SEM } & p-value \\
\cline { 2 - 3 } & NS $^{1)}$ & HS $^{2)}$ & & \\
\hline Total amino acids $(\mu \mathrm{mol} / \mathbf{L})$ & 947.8 & $1,198.7$ & 38.38 & $<0.01$ \\
Ala & 111.1 & 176.7 & 12.69 & $<0.01$ \\
Arg & 4.70 & 4.05 & 0.541 & 0.42 \\
Asn & 15.7 & 15.2 & 1.30 & 0.82 \\
Asp & 3.90 & 5.30 & 0.483 & 0.08 \\
Gln & 105.3 & 113.3 & 8.11 & 0.24 \\
Glu & 14.6 & 22.0 & 1.82 & 0.02 \\
Leu & 135.2 & 137.1 & 5.86 & 0.83 \\
Ile & 80.3 & 77.0 & 6.31 & 0.72 \\
Lys & 3.23 & 2.16 & 0.228 & 0.01 \\
Met & 17.6 & 19.6 & 0.96 & 0.19 \\
Phe & 34.1 & 37.7 & 1.96 & 0.24 \\
Thr & 39.2 & 51.4 & 2.95 & 0.02 \\
Trp & 22.6 & 27.8 & 2.10 & 0.11 \\
Tyr & 37.0 & 41.6 & 2.60 & 0.25 \\
Val & 163.0 & 167.4 & 9.03 & 0.74 \\
Gly & 99.2 & 180.7 & 12.60 & $<0.01$ \\
\hline
\end{tabular}

NS, non-heat stress group; HS, heat stress group; SEM, standard error of the mean.

1) Cows were raised in autumn.

${ }^{2)}$ Cows were raised in summer.

enzymes [15]. Our results suggested that heat stress might impair antioxidative ability via the depletion of enzymatic antioxidants.

It was observed that heat stress decreased DMI of dairy cow in our study. It was in accordance with a previous report, which reported that DMI was the most sensitive to air temperature [16]. However, DMI and digestive requirements increase with the increase of milk yield of dairy cow. Thus, inadequate feed intake caused by heat stress is responsible for decreased milk production. Moreover, Scott et al [17] has suggested that the DMI affects blood glucose concentration and subsequent conversion to lactose in the mammary gland. Lactose is the main osmotic regulator of lactation which can improve milk production. In the present study, heat-stressed cows had lower concentration of blood glucose, which could explain the lower milk yield in summer. In addition, NRC [8] has suggested that maintenance expenditure at $35^{\circ} \mathrm{C}$ increase by $20 \%$ over thermoneutral condition, thus increasing the cow's energy expenditure, often at the expense of milk yield. Per THI unit increase would decrease $0.88 \mathrm{~kg}$ milk yield during hot weather [16]. Our results indicated that the decline of DMI and increase of maintenance expenditure could be a major cause of reducing production of heat-stressed cows.

Our results showed that heat stress reduced insulin level of dairy cows, which might be due to lower concentration of blood glucose. De Rensis and Scaramuzzi [18] has reported that heat stress decreased DMI of dairy cows and inhibited nutrient absorption, resulting in low concentration of blood glucose and insulin. Moreover, reduction of DMI in heat-stressed dairy cows prolongs the period of negative energy balance and leads to increased concentration of NEFA [18]. Elevated NEFA causes pancreas $\beta$-cell apoptosis and decreases insulin secretory capacity [19]. Excessive NEFA might have inhibited insulin secretion in our study. In addition, a reduction of insulin level with increasing temperature is due to the reduction in heat production [20]. However, pairfeeding experiment of heat stress has shown that heat-stressed cows have higher insulin level [21]. These inconsistent results might be due to different DMI of thermal-neutral cows.

In the present experiment, total amino acid concentrations in plasma was increased in heat-stressed dairy cows. Due to nutrient deficiency, the capacity of amino acid catabolism is likely reinforced in the liver, and amino acid concentrations are increased in plasma [22]. Additionally, higher concentrations of Glu, Gly, and Asp were observed in heat-stressed dairy cows. These results are consistent with the reports of Ai et al [23], who found that amino acids (Glu, Gly, Asp, and Val) for gluconeogenesis were higher in heat-stressed cows. When plasma glucose level is low, more limited utilization of amino acids for gluconeogenesis is observed in heat-stressed cows [6]. In addition, previous study has reported that Ala can regulate gluconeogenesis and glycolysis to ensure glucose production during periods of food deprivation [24]. We found higher Ala concentration in heat-stressed dairy cows, indicating that gluconeogenesis was likely reinforced under heat stress. It is reported that $\mathrm{Thr}$ is involved in immune function [25]. Higher concentrations of Thr would be associated with immune response under heat stress. However, lower Lys concentration of heat-stressed cows was observed in the present study. Lys is inadequately synthesized by the body relative to needs and needs be provided from the diet. Lower Lys concentration could be due to reduction of DMI and Lys intake in our study. The decreased Lys concentrations may limit milk protein synthesis [26]. Our results suggested that amino acids may be less used to synthesize milk protein under heat stress, but rather involved in immune response and gluconeogenesis.

Seasonal variation of milk protein level is influenced by various factors such as dietary factors, managerial factors, and climatic conditions. Constant managerial conditions and diets were maintained during the trial periods, which facilitated the observation of the effect of climatic conditions on milk protein. Heat-stressed dairy cows had lower milk protein content in our study, which is defined as "heat-stressed milk protein decrease syndrome". We found that reduction of milk protein content might be due to low level of circulating insulin. Burgos et al [27] has reported that insulin is a potent anabolic hormone and which can promote mammary protein synthesis. In addition, competition for amino acids that supply both milk protein and maintenance metabolism could be a possible reason of the decreased milk protein content under heat stress. Dairy cows could utilize more intensive amino acids as precursors for gluconeogenesis during heat stress [28]. Immune response and gluconeogenesis depleted a large number of amino acids, thus decreased the availability of amino acids for milk protein synthesis in our study. Similarly, Cowley et al [6] also has reported that the synthesis of the heat shock proteins may 
decrease the availability of amino acids for milk protein synthesis. However, Naderi et al [29] has suggested that substituting beet pulp for corn silage in the diet of heat-stressed cows results in a high milk protein content, corresponding to low rumen ammonianitrogen concentration and milk urea concentration. Heat-stressed cows fed the protein containing high Lys could increase milk yield and milk protein yield [30]. The exact mechanisms need to be further studied.

\section{CONCLUSION}

In summary, the results from the current study indicate that heat stress reduces milk protein content, glucose and insulin concentrations in blood, and changes amino acids profile of dairy cows, suggesting that more amino acids are required for maintenance (immune response and gluconeogenesis) but not for milk protein synthesis under heat stress, which provides scientific experimental bases for how to alleviate the detrimental effect of heat stress in dairy cow production.

\section{CONFLICT OF INTEREST}

We certify that there is no conflict of interest with any financial organization regarding the material discussed in the manuscript.

\section{ACKNOWLEDGMENTS}

This research was supported by National Natural Science Foundation of China (31372341) and Ministry of Science and Technology of China (No.2012BAD12B02-5), and the Agricultural Science and Technology Innovation Program (ASTIP-IAS07). The authors thank the MOA-Milk and Dairy Product Inspection Center (Beijing) for assistance on laboratory analysis, and the persons for their assistance of sampling.

\section{REFERENCES}

1.Bernabucci U, Basiricò L, Morera P, et al. Effect of summer season on milk protein fractions in Holstein cows. J Dairy Sci 2015;98:1815-27.

2.Smith DL, Smith T, Rude BJ, Ward SH. Short communication: Comparison of the effects of heat stress on milk and component yields and somatic cell score in Holstein and Jersey cows. J Dairy Sci 2013;96: 3028-33.

3.Archer SC, Mc CF, Wapenaar W, Green MJ. Association of season and herd size with somatic cell count for cows in Irish, English, and Welsh dairy herds. Vet J 2013;196:515-21.

4.Baumgard LH, Wheelock JB, Sanders SR, et al. Postabsorptive carbohydrate adaptations to heat stress and monensin supplementation in lactating Holstein cows. J Dairy Sci 2011;94:5620-33.

5.Wang JP, Bu DP, Wang JQ, et al. Effect of saturated fatty acid supplementation on production and metabolism indices in heat-stressed mid-lactation dairy cows. J Dairy Sci 2010;93:4121-7.
6.Cowley FC, Barber DG, Houlihan AV, Poppi DP. Immediate and residual effects of heat stress and restricted intake on milk protein and casein composition and energy metabolism. J Dairy Sci 2015;98: 2356-68.

7.Flynn NE, Knabe DA, Mallick BK, Wu G. Postnatal changes of plasma amino acids in suckling pigs. J Anim Sci 2000;78:2369-75.

8. National Research Council. Effect of environment on nutrient requirement of domestic animals. Washington, DC: National Academy Press; 1981.

9.AOAC International. Official Methods of Analysis. 18th ed. Gaithersburg, MD: AOAC International; 2005.

10. Matsubara C, Nishikawa Y, Yoshida Y, Takamura K. A spectrophotometric method for the determination of free fatty acid in serum using acyl-coenzyme A synthetase and acyl-coenzyme A oxidase. Anal Biochem 1983;130:128-33.

11. Cheng JB, Bu DP, Wang JQ, et al. Effects of rumen-protected $\gamma$-aminobutyric acid on performance and nutrient digestibility in heat-stressed dairy cows. J Dairy Sci 2014;97:5599-607.

12. Liu LL, He JH, Xie HB, et al. Resveratrol induces antioxidant and heat shock protein mRNA expression in response to heat stress in blackboned chickens. Poult Sci 2014;93:54-62.

13. Zuo L, Christofi FL, Wright VP, et al. Intra- and extracellular measurement of reactive oxygen species produced during heat stress in diaphragm muscle. Am J Physiol-cell Physiol 2000;279:1058-66.

14. Halliwell B, Chirico S. Lipid peroxidation: its mechanism, measurement, and significance. Am J Clin Nutr 1993;57:715S-24S.

15. Mujahid A, Akiba Y, Warden CH, Toyomizu M. Sequential changes in superoxide production anion carriers and substrate oxidation in skeletal muscle mitochondria of heat-stressed chickens. FEBS Lett 2007;581:3461-7.

16. West JW. Effects of heat-stress on production in dairy cattle. J Dairy Sci 2003;86:2131-44.

17. Scott RA, Bauman DE, Clark JH. Cellular gluconeogenesis by lactating bovine mammary tissue. J Dairy Sci 1976;59:50-6.

18. De Rensis F, Scaramuzzi RJ. Heat stress and seasonal effects on reproduction in the dairy cow-a review. Theriogenology 2003;60:1139-51.

19. Cooksey RC, Jouihan HA, Ajioka RS, et al. Oxidative stress, $\beta$-cell apoptosis, and decreased insulin secretory capacity in mouse models of hemochromatosis. Endocrinology 2004;145:5305-12.

20. Haque N, Ludri A, Hossain SA, Ashutosh M. Alteration of metabolic profiles in young and adult Murrah buffaloes exposed to acute heat stress. Iran J Appl Anim Sci 2012;1:23-9.

21. Wheelock JB, Rhoads RP, VanBaale MJ, Sanders SR, Baumgard LH. Effects of heat stress on energetic metabolism in lactating Holstein cows. J Dairy Sci 2010;93:644-55.

22. Stahel P, Purdie NG, Cant JP. Use of dietary feather meal to induce histidine deficiency or imbalance in dairy cows and effects on milk composition. J Dairy Sci 2014;97:439-45.

23. Ai Y, Cao Y, Xie ZE, Zhang YS, Shen XZ. Relationship between free amino acids in cow's blood and decreasing milk protein under heat stress. Food Sci 2015;11:38-41.

24. Meijer AJ. Amino acids as regulators and components of nonprotein- 
ogenic pathways. J Nutr 2003;133:2057S-62S.

25. Wu G. Amino acids: metabolism, functions, and nutrition. Amino Acids 2009;37:1-17.

26. Nan XM, Bu DP, Li XY, et al. Ratio of lysine to methionine alters expression of genes involved in milk protein transcription and translation and mTOR phosphorylation in bovine mammary cells. Physiol Genomics 2014;46:268-75.

27. Burgos SA, Dai M, Cant JP. Nutrient availability and lactogenic hormones regulate mammary protein synthesis through the mammalian target of rapamycin signaling pathway. J Dairy Sci 2010;93:153-61.

28. Koch F, Lamp O, Eslamizad M, Weitzel J, Kuhla B. Metabolic response to heat stress in late-pregnant and early lactation dairy cows: implications to liver-muscle crosstalk. PloS one 2016;11:e0160912.

29. Naderi N, Ghorbani GR, Sadeghi-Sefidmazgi A, Nasrollahi SM, Beauchemin KA. Shredded beet pulp substituted for corn silage in diets fed to dairy cows under ambient heat stress: feed intake, totaltract digestibility, plasma metabolites, and milk production. J Dairy Sci 2016;99:8847-57.

30. Chen KH, Huber JT, Theurer CB, et al. Effect of protein quality and evaporative cooling on lactational performance of Holstein cows in hot weather. J Dairy Sci 1993;76:819-25. 